\title{
The DIEP Flap as Well-established Method of Choice for Autologous Breast Reconstruction with a Low Complication Rate - Retrospective Single-centre 10-Year Experience
}

\section{Die freie DIEP-Lappenplastik als komplikationsarme und etablierte Methode der Wahl zur autologen Rekonstruktion der Brust - Retrospektive Analyse aus 10 Jahren Single-Center-Erfahrung}

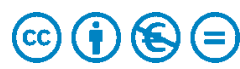

Authors

Beatrix Munder ${ }^{1}$, Christoph Andree ${ }^{1}$, Christian Witzel ${ }^{1}$, Sonia Fertsch ${ }^{1}$, Peter Stambera ${ }^{1}$, Tino Schulz ${ }^{1}$, Olaf Fleischer ${ }^{1}$, Mazen Hagouan ${ }^{1}$, Lukas Grüter ${ }^{1}$, Birgit Aufmesser ${ }^{1}$, Katinka Staemmler ${ }^{1}$, Julia Kornetka ${ }^{1}$, Mohammed Aldeeri ${ }^{1}$, Katrin Seidenstücker ${ }^{1}$, Alina Abu-Ghazaleh ${ }^{1}$, Andreas Wolter ${ }^{1,2}$

Affiliations

1 Klinik für Plastische und Ästhetische Chirurgie, Sana Kliniken Düsseldorf GmbH, Düsseldorf, Germany

2 Universität Witten-Herdecke, Fakultät für Gesundheit, Witten, Germany

Key words

breast, breast cancer, breast reconstruction, DIEP flap, autologous breast reconstruction, BRCA

Schlüsselwörter

Mamma, Mammakarzinom, Brustrekonstruktion, DIEP-Lappen, autologe Brustrekonstruktion, BRCA

received 27.10.2018

revised 9.2 .2020

accepted 10.2.2020

Bibliography

DOI https://doi.org/10.1055/a-1116-2102

published online 16.4.2020 | Geburtsh Frauenheilk 2020; 80: 628-638 @ Georg Thieme Verlag KG Stuttgart · New York । ISSN 0016-5751

Correspondence

Dr. med. Beatrix Munder

Klinik für Plastische und Ästhetische Chirurgie,

Sana Kliniken Düsseldorf GmbH

Gräulinger Straße 120, 40625 Düsseldorf, Germany

beatrix.munder@sana.de

$\Theta$

Deutsche Version unter:

https://doi.org/10.1055/a-1116-2102
ABSTRACT

Background Breast cancer is the most common cancer affecting women in Germany. Despite breast-conserving therapy (BCT) being carried out in almost $70 \%$ of cases, a high number of women still require complete mastectomy. Prophylactic mastectomy is also indicated for women with a BRCA $1 / 2$ gene mutation. In addition to implant-based heterologous breast reconstruction, autologous breast reconstruction using a DIEP flap has been found to be beneficial, particularly for patients who had prior radiotherapy. This study aims to show that DIEP flap reconstruction surgery is the method of choice for autologous breast reconstruction with a low rate of complications.

Patients and Methods Autologous breast reconstruction using a DIEP flap was performed in 1124 patients between July 2004 and December 2014. Retrospective study criteria included potential risk factors such as age, BMI, smoking, chemotherapy and/or radiotherapy, and comorbidities as well as outcome parameters such as postoperative complications. Outcomes were evaluated with a mean follow-up of 24 months.

Results A total of 1124 patients underwent 1274 free DIEP flap breast reconstructions, of which 150 were bilateral reconstructions. The primary indication was previous mastectomy in 785 cases, followed by prior implant-based reconstruction in 265 cases. The total flap loss rate was $0.6 \%$. Postoperative surgical revision for abdominal wall hernia was required in $0.2 \%$ of cases. The group with a higher BMl and the group of smokers had significantly higher complication rates. Elderly patients (> 65 years), patients who had undergone chemo-/ radiotherapy and patients with diabetes did not have higher complication rates.

Conclusion DIEP flap surgery is an excellent option for autologous breast reconstruction, with a low rate of donor site morbidity and low complication rates. DIEP flap surgery car- 
ried out in a specialised interdisciplinary breast centre in a standardised clinical setting after prior careful patient selection to take account of risk factors such as high BMI and smoking is a reliable method with a low complication rate and satisfactory long-term reconstruction results.

\section{ZUSAMMENFASSUNG}

Hintergrund Das Mammakarzinom ist die häufigste Krebserkrankung der Frau in Deutschland. Trotz ca. 70\% brusterhaltender Therapien (BET), verbleibt eine hohe Anzahl an Frauen, bei denen eine vollständige Brustdrüsenentfernung notwendig ist. Hinzu kommt die Indikation zur prophylaktischen Mastektomie bei Nachweis einer Genmutation (z. B. BRCA-1/ 2). Neben der heterologen implantat-basierten Brustrekonstruktion, kann sich die autologe Brustrekonstruktion per DIEP-Lappenplastik im Langzeitverlauf als vorteilhaft erweisen, insbesondere nach vorausgegangener Radiatio. In dieser Studie soll gezeigt werden, dass die DIEP-Lappenplastik unter standardisierten Bedingungen ein komplikationsarmes zuverlässiges Verfahren zur Eigengewebsrekonstruktion darstellt.

Patienten und Methoden Von 07/2004 bis 12/2014 wurde bei 1124 Patientinnen eine autologe Brustrekonstruktion mittels DIEP-Lappenplastik durchgeführt. Retrospektive Unter- suchungskriterien beinhalteten potenzielle Risikofaktoren wie Alter, BMI, Nikotinkonsum, Chemotherapie und/oder Radiatio, Vorerkrankungen sowie als Outcomeparamter das Auftreten von postoperativen Komplikationen. Der mittlere Nachbeobachtungszeitraum lag bei 24 Monaten.

Ergebnisse Es wurden bei 1124 Patientinnen 1274 freie DIEP-Lappenplastiken durchgeführt, davon 150 bilaterale Rekonstruktionen. Hauptindikation war in 785 Fällen eine vorausgegangene Mastektomie, gefolgt von 265 Fällen mit vorausgegangener Implantat-basierter Rekonstruktion. Die Lappenvollverlustrate betrug $0,6 \%$. In $0,2 \%$ wurde eine postoperative Revision einer Bauchwandhernie erforderlich. Die Komplikationsrate war in der Gruppe mit erhöhtem BMI und der Raucher signifikant erhöht. Die Gruppe der Patientinnen > 65 Jahre zeigte kein Risiko für eine erhöhte Komplikationsrate.

Schlussfolgerung Die DIEP-Lappenplastik stellt unter Berücksichtigung einer sorgfältigen Patientinnenselektion hinsichtlich Risikofaktoren, wie erhöhter BMI und Nikotinabusus, in einem standardisierten Umfeld innerhalb eines spezialisierten Interdisziplinären Brustzentrums eine komplikationsarme Methode mit geringer Hebestellenmorbidität dar, um eine ästhetisch langfristig zufriedenstellende Wiederherstellung der weiblichen Brustform zu erreichen.

\section{Introduction}

Every year, around 75000 women in Germany develop breast cancer. This means that breast cancer continues to be the most common cancer affecting women in Germany. The mean age at onset of disease is lower than with other forms of cancer. One in four women is younger than 55 years at diagnosis and one in ten women is younger than 45 years (Robert Koch Institute, Centre for Cancer Registry Data, [1]).

Around $70 \%$ of affected women can be treated with breastconserving therapy (BCT) consisting of lumpectomy followed by radiotherapy. The indication for chemotherapy is decided on a case-by-case basis, and radiotherapy is usually prescribed in addition to oncological surgery. The decision to perform mastectomy, i.e. surgical removal of the entire breast, is guided by the tumour stage, an unfavourable breast size to tumour size ratio and the presence of multifocal or inflammatory carcinoma [2,3]. Other inclusion criteria for mastectomy are recurrence after BCT with contraindication of radiation therapy.

Breast reconstruction after complete breast removal can result in a significant improvement in quality of life [4]. Carriers of the heterozygous BRCA $1 / 2$ gene mutation (BReast CAncer) or other gene mutations (high risk [OR > 5.0]: BRCA1/2, PALP2; moderate risk [OR 1.5-5.0]: RAD51C, ATM, BRIP1, CDH1, CHEK2, NBN, PTEN, etc.) have a progressive and significantly increased risk of developing breast cancer or ovarian cancer over the course of their lives [5-7]. In addition to attending regular screening programmes, these patients are given information on how they can reduce their risk, for example, by undergoing a bilateral mastectomy. Describing the different available procedures for breast reconstruction is mandatory in this context.
Autologous reconstruction is an option in addition to implantbased heterological procedures. Autologous reconstruction results in a reconstructed breast which moves more naturally and is comparable to the contralateral breast, showing similar behaviour in terms of weight fluctuation and natural ageing processes. Patients do not usually report a foreign body sensation.

Historically, pedicled transverse rectus abdominis muscle (TRAM) flap was the method of choice for autologous (own tissue) breast reconstruction [8]. Advances in reconstruction techniques and the development of free microvascular tisse transfer led to the introduction of free TRAM flap procedures, first reported by Grotting et al. in 1989 [9]. The same year saw the first published description of a purely adipocutaneous free microvascular tissue transfer from the lower abdomen, pedicled using the proximal inferior deep epigastric artery with its larger diameter and the inferior epigastric vein (DIEA/DIEV) [10]. This procedure no longer required the inclusion of muscle tissue in the flap. Moreover, the new technique preserved the segmental innervation of the rectus muscle. The procedure was refined even further, and the first description of breast reconstruction using a deep inferior epigastric artery perforator (DIEP) flap was published in 1994 by Allen and Treece [11], followed by Blondeel and Boeckx [12]. This technique preserves the stability and integrity of the abdominal wall.

This retrospective single-centre study aims to show that today, DIEP flap surgery is a reliable procedure for autologous breast reconstruction with a low rate of complications. The study focuses on risk factors (age, BMI, diabetes mellitus, and smoking) and their potential association with complications in the study population. We present the results of this procedure carried out over the past 10 years in our department in an interdisciplinary breast centre. The results were compiled in close cooperation with our 
in-house senology department and focused on outcomes following autologous microsurgical tissue breast reconstruction.

\section{Patients and Methods}

This retrospective study complies with the current version of the Declaration of Helsinki guidelines and the guidelines of the International Committee of Medical Journals Editors (ICMJE). Approval and consent of the ethics committee were not required. Data for the well-established standard reconstructive (DIEP flap) procedure were retrospectively anonymised and analysed.

\section{Patient selection}

Between July 2004 and December 2014, we performed autologous DIEP flap breast reconstruction using tissue from the lower abdomen in 1124 patients admitted to Sana Hospital in Düsseldorf-Gerresheim. Data were retrospectively evaluated. Patients were referred to our hospital by our in-house or affiliated senology or gynaecology departments, gynaecologists in private practice or at their own request. All patients who underwent DIEP flap surgery for autologous tissue reconstruction based on any of the following indications were included in the study. Indications were primary reconstruction after modified radical mastectomy and/ or prophylactic mastectomy for verified gene mutation (e.g. $B R C A 1 / 2$, etc.), cosmetically unsatisfactory outcome after BCT, and foreign body sensation and/or capsular fibrosis after implant-based reconstruction. Patients who required breast reconstruction with a significantly larger portion of the rectus abdominis muscle (ms-[muscle-sparing] TRAM or TRAM flap) intraoperatively due to perforator insufficiency were excluded from the study.

Absolute contraindications and additional exclusion criteria for the study and therefore for autologous tissue reconstruction with a DIEP flap included previous delay surgery (ligature of the inferior epigastric vascular system in preparation for a pedicled TRAM flap) as well as serious comorbidities. Relative contraindications included previous abdominal or thoracic surgery and abdominal scarring.

Additional examination criteria in this study included possible risk factors such as BMI (body mass index), smoking, previous chemotherapy and/or radiation therapy, age, and diabetes mellitus. Outcome parameters were defined as the development of postoperative complications at the donor or recipient site including the flap itself. Complications were differentiated into breast-related complications such as full or partial flap loss and flap edge or fat necrosis and donor site-related complications such as development of a hernia or seroma.

Data collection was carried out using a preoperative and postoperative documentation algorithm. The collected data were then transferred into Excel. The ward physician, the physician who examined the patient on an outpatient basis, and the surgeon who performed the reconstruction all completed detailed forms. Patients presented to our outpatient department for follow-up at 2 weeks, 6 weeks, 3 months, 1 year and 4 years after surgery or were questioned by telephone interview. The mean follow-up time was 24 months (12-48 months).

\section{Anatomy and surgical technique}

The abdominal wall is perfused by the superior, inferior and superficial epigastric arteries, which communicate with one another. Arterial blood is primarily supplied via the deep vascular system, although venous drainage partially occurs through the superficial vascular network. Multiple perforator vessels arise cranially along the course of the deep inferior epigastric artery (DIEA). After passing through the rectus muscle, the perforators branch off as they reach the hypodermis to perfuse the skin and the subdermal layers. The surgical technique is based on this concept. Perforator vessels usually provide the arterial supply or venous drainage of the entire flap. All patients undergo CT angiography preoperatively to visualise the perforator vessels. As with radiological CT mapping, the precise location of the perforators can be verified by intraoperative Doppler evaluation.

In flap surgery, the preferred connector vessels at the recipient site are the internal mammary vessels (internal mammary artery/ internal mammary vein, IMA/IMV). They take a parasternal and retrocostal course. Vascular anastomoses are performed at the level of the third or fourth rib. Flap dissection and dissection of the connecting vessels are done using a two-team approach, i.e., by two surgical teams each consisting of a surgeon and assistants.

Surgery is carried out under general anaesthesia with the patient in a supine position. The shape of the incision is similar to that used for an abdominoplasty, that is, it takes the form of an ellipsoidal incision on the lower abdomen. The superficial inferior epigastric vein (SIEV) should always be dissected along a length of $5 \mathrm{~cm}$ to serve as a "lifeboat" for venous supercharging in the event of venous congestion. After incising around the SIEV to reach the abdominal wall fascia, dissection using bipolar forceps is continued along the epifascial plane from lateral to medial while taking care to preserve the perforator vessels. The aim during the initial flap raise is to detect the perforator which can be used to perfuse the adipocutaneous flap. This is then dissected free of the rectus muscle until the inferior epigastric artery and vein are reached while ensuring that segmental innervation is preserved ( $\mathbf{F i g} \mathbf{1} \mathbf{1}$ ). After the flap has been dissected off, the epigastric artery and vein are microanastomosed to the internal thoracic vessels. A venous coupler device (diameter: $1.5-3.0 \mathrm{~mm}$ ) is usually used to anastomose the DIEV (usually two DIE veins) to the cranial IMV. Use of a venous coupler became part of the standard procedure in 2012. Since that time, suturing of the venous anastomosis with 9-0 Ethilon single button sutures is only done if there is a pronounced diameter mismatch or if using a venous coupler is technically impossible. If necessary, a second anastomosis is performed to connect the vena comitans of the DIEV to the second IMV or connect the SIEV to the distal IMV or the second IMV (if present) for supercharging if there are signs of venous congestion or insufficiency. In very rare cases, in-flap anastomosis of the SIEV to the DIEV or its vena comitans is done to improve venous drainage. The artery is sutured using 9-0 monofilament single button sutures. Then 2500 IE heparin is administered by intravenous infusion.

This is followed by the actual breast reconstruction, in which the DIEP flap is shaped into a breast. Abdominal skin can be used for reconstruction if there is no soft tissue mantle for the breast, for example when operating on patients who have had complete 


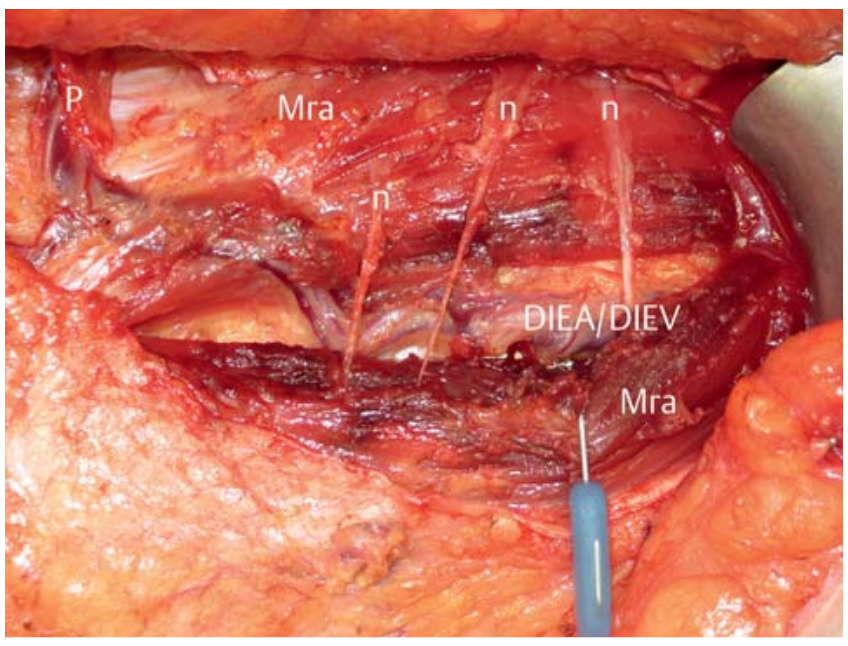

- Fig. 1 Intraoperative site after initial DIEP flap raise. The intercostal nerves (n) which were preserved to innervate the rectus abdominis muscle (Mra) and the perforators ( $P$ ) which pass through the rectus abdominis muscle to the deep inferior epigastric artery and vein (DIEA/DIEV) are dissected.

- Table 1 Basic demographic data.

\begin{tabular}{|l|l|}
\hline & $\begin{array}{l}\text { Total number } \\
\text { of patients } \\
\text { ( } \mathbf{n}=1124)\end{array}$ \\
\hline Age (years) & $50(\mathrm{SD} \pm 8.70)$ \\
\hline BMI $\left(\mathrm{kg} / \mathrm{m}^{2}\right)$ & $25.6(\mathrm{SD} \pm 3.8)$ \\
\hline - Underweight $\left(<18.5 \mathrm{~kg} / \mathrm{m}^{2}\right)$ & $6(0.5 \%)$ \\
\hline - Normal weight $\left(18.5\right.$ to $\left.\leq 25 \mathrm{~kg} / \mathrm{m}^{2}\right)$ & $496(44.1 \%)$ \\
\hline - Overweight $\left(25\right.$ to $\left.\leq 30 \mathrm{~kg} / \mathrm{m}^{2}\right)$ & $452(40.2 \%)$ \\
\hline - Obese $\left(30\right.$ to $\left.\geq 40 \mathrm{~kg} / \mathrm{m}^{2}\right)$ & $170(15.2 \%)$ \\
\hline Duration of surgery $(\mathrm{minutes})$ & $312(\mathrm{SD}$ \\
& $\pm 390.52) ;$ \\
& $(305$ unilateral, \\
\hline Smoker & 436 bilateral) \\
\hline Patients with diabetes & $\mathrm{n}=133(11.8 \%)$ \\
\hline Status post chemotherapy & $\mathrm{n}=5(0.4 \%)$ \\
\hline Status post radiotherapy & $\mathrm{n}=763(67.9 \%)$ \\
\hline BMI: body mass index, SD: standard deviation & $\mathrm{n}=662(58.9 \%)$ \\
\hline
\end{tabular}

mastectomy/mammectomy. The greater part of the flap is used for the reconstruction of breast volume. The shape and size of the reconstructed breast are individually adapted to the shape and size of the contralateral breast in accordance with the patient's wishes. If necessary, patients with macromastia or pronounced ptosis of the healthy breast may require reduction of the contralateral healthy breast at 2-3 months after autologous flap reconstruction. Reconstruction of the nipple-areola complex using a skate/star flap or nipple-sharing may be considered after a further 2-3 months.

\section{Statistical analysis}

Statistical analysis of subgroups was done using Microsoft Excel 2010 (Microsoft Corporation, Redmond, USA) and IBM SPSS statistics (v. 19.0). Fisher's Exact test and $x^{2}$ test were used for statistical evaluation, and statistical significance was set at a p-value of $<0.05$. Patient age, BMI, smoking, diabetes mellitus, chemotherapy, and previous radiation therapy were determined as the influencing or risk factors. The outcome parameters were defined as the occurrence of complications (flap-related complications and donor site and recipient site-related complications).

\section{Results}

Between July 2004 and December 2014, we performed 1274 DIEP flap reconstruction procedures in 1124 women. Mean patient age was 50 (SD \pm 8.70 ) years. The mean duration of surgery was 312 ( $\mathrm{SD} \pm 390.52$ ) minutes (mean duration for unilateral procedures: 305 minutes, mean duration for bilateral reconstruction: 436 minutes) ( $\bullet$ Table 1$)$.

In 785 cases, the indication for autologous tissue reconstruction was made after prior MRM (modified radical mastectomy), in 261 cases after having previously undergone implant-based reconstruction (144 cases had symptomatic capsular fibrosis, 78 cases had an aesthetically unsatisfactory result and 43 cases had a combination of the two), in 67 cases after prior BCT with a cosmetically unsatisfactory result, and in 8 cases after prior latissimus dorsi flap reconstruction with an implant ( $\bullet$ Table 2 ).

Bilateral reconstruction was performed in 150 patients and unilateral reconstruction in 974 patients. Secondary unilateral reconstruction was done in 933 cases and secondary bilateral reconstruction in 109 cases. Primary unilateral reconstruction was carried out in 41 patients and primary bilateral reconstruction in 18 patients. 23 patients had primary unilateral and secondary contralateral reconstruction ( $\vee$ Table 3 ). BRCA 1/BRCA 2 mutations were detected in 46 and 11 patients, respectively.

The total rate of complications compared to the total number of flap procedures was $11.7 \%$; the complete flap loss rate was $0.6 \%$ and the partial flap loss rate was $0.9 \%$. Anastomosis revision was required in 1 patient $(0.1 \%$ ) because of impaired arterial perfusion and in 10 patients $(0.8 \%)$ for venous drainage disorders. Flap edge necrosis $(<10 \%)$ occurred in 32 patients who had undergone flap reconstruction (2.5\%). Breast haematoma requiring revision occurred in $1.3 \%$ of patients, and abdominal haematoma requiring revision occurred in $0.4 \%$ of patients. Postoperative secondary revision for abdominal wall hernia occurred in $0.2 \%$ of patients. Abdominal wound healing disorders developed in $0.5 \%$ of cases. $3.6 \%$ of patients had fat necrosis requiring revision surgery while seroma requiring revision occurred in $0.5 \%$ of patients ( $\bullet$ Table 4). Conventional venous suturing using 9-0 Ethilon single button sutures was performed in 968 cases (76\%), while a venous coupler was used in the other patients. After 2012, venous couplers were used as part of the standard procedure. No bipedicled DIEP flap reconstructions were performed for unilateral reconstruction. In 6 cases, the SIEV was used to create an in-flap anastomosis for venous supercharging. No statistical correlation was found between venous suturing or the choice of anastomosis and the occurrence of flap-specific complications. 
- Table 2 Indication for autologous tissue reconstruction (DIEP flap). The majority of reconstructions were performed in patients who were status post modified radical mastectomy (MRM). Complications following implant-based reconstruction were the second most common indication for DIEP flap reconstruction, followed by unsatisfactory outcomes after breast-conserving therapy (BCT).

\begin{tabular}{|c|c|c|c|}
\hline Indication for reconstruction & Percent & N & \\
\hline 1. s/p MRM & $69.8 \%$ & 785 & \\
\hline $\begin{array}{l}\text { 2. s/p BCT with cosmetically } \\
\text { unsatisfactory outcome }\end{array}$ & $6.0 \%$ & 67 & \\
\hline 3. s/p LD flap and implant & $0.6 \%$ & 7 & \\
\hline $\begin{array}{l}\text { 4. s/p implant-based } \\
\text { reconstruction }\end{array}$ & $23.6 \%$ & 265 & \\
\hline $\begin{array}{l}\text { a) symptomatic capsular } \\
\text { contracture }\end{array}$ & $54.4 \%$ & & 144 \\
\hline $\begin{array}{l}\text { b) aesthetically unsatisfac- } \\
\text { tory result }\end{array}$ & $29.4 \%$ & & 78 \\
\hline c) both (a and b) & $16.2 \%$ & & 43 \\
\hline
\end{tabular}

s/p: status post, MRM: modified radical mastectomy, BCT: breastconserving therapy, LD: latissimus dorsi

- Table 3 Type of DIEP flap reconstruction. More than three quarters of surgeries were secondary unilateral procedures. $10 \%$ were secondary bilateral reconstructions, most of which were carried out for breast reconstruction following prophylactic breast removal in women with $B R C A 1 / 2$ gene mutations.

\begin{tabular}{|l|c|r|}
\hline Type of reconstruction & Percent & \multicolumn{1}{|c|}{$\mathbf{n}$} \\
\hline 1. primary unilateral reconstruction & $3.6 \%$ & 41 \\
\hline 2. secondary unilateral reconstruction & $83.0 \%$ & 933 \\
\hline $\begin{array}{l}\text { 3. unilateral primary and contralateral } \\
\text { secondary reconstruction }\end{array}$ & $2.1 \%$ & 23 \\
\hline 4. bilateral primary reconstruction & $1.6 \%$ & 18 \\
\hline 5. bilateral secondary reconstruction & $9.7 \%$ & 109 \\
\hline
\end{tabular}

\section{Subgroup analysis with respect to BMI}

As regards BMI (body mass index) distribution, 0.5\% (6 patients) of our cohort were underweight (BMI $\left.<18.5 \mathrm{~kg} / \mathrm{m}^{2}\right), 44.1 \%$ (496 patients) were normal weight (BMI 18.5 to $\leq 25 \mathrm{~kg} / \mathrm{m}^{2}$ ), $40.2 \%$ (452 patients) were overweight (BMI 25 to $\leq 30 \mathrm{~kg} / \mathrm{m}^{2}$ ) and $15.2 \%$ (170 patients) were obese (BMI 30 to $\geq 40 \mathrm{~kg} / \mathrm{m}^{2}$ ). Complications requiring surgery occurred in 43 patients in the normal weight group, 79 patients in the overweight group and 26 patients in the obese group. The risk of developing complications requiring surgery was significantly higher in the patient groups with a higher BMI ( 25 to $\leq 30$ and 30 to $\geq 40 \mathrm{~kg} / \mathrm{m}^{2}$ ) compared to the group of normal weight patients $(p<0.05)$. Rates of flap edge and fat necrosis were statistically significantly higher in both the overweight group (BMI 25 to $\leq 30 \mathrm{~kg} / \mathrm{m}^{2}$ ) and the obese group (BMI 30 to $\geq 40 \mathrm{~kg} / \mathrm{m}^{2}$. The rate of acute flap revisions for venous insufficiency was also significantly higher in the obese group (BMI 30 to $\geq 40 \mathrm{~kg} / \mathrm{m}^{2}$ ) ( $\triangleright$ Table 5 ).
- Table 4 Total complications.

\begin{tabular}{|l|c|c|}
\hline Number of patients & 1124 & \\
\hline Number of DIEP flap procedures & 1274 & \\
\hline Complications & Flap-related & $\%$ \\
\hline Total number of complications & 148 & $11.7 \%$ \\
\hline Total flap loss & 8 & $0.6 \%$ \\
\hline Partial flap loss > 20\% of the flap & 12 & $0.9 \%$ \\
\hline Insufficient arterial supply & 1 & $0.1 \%$ \\
\hline Inadequate venous drainage & 10 & $0.8 \%$ \\
\hline Flap edge necrosis < 10\% of the flap & 32 & $2.5 \%$ \\
\hline Breast haematoma & 17 & $1.3 \%$ \\
\hline Fat necrosis & 47 & $3.6 \%$ \\
\hline Abdominal haematoma & 5 & $0.4 \%$ \\
\hline Abdominal wall hernia & 3 & $0.2 \%$ \\
\hline Impaired abdominal wound healing & 7 & $0.5 \%$ \\
\hline Abdominal wall seroma & 6 & $0.5 \%$ \\
\hline
\end{tabular}

\section{Smoking}

At the time of surgery, 133 patients reported that they were smokers, of whom $31.6 \%(n=42)$ suffered complications requiring surgery. At the time of surgery, 991 patients were non-smokers, of whom 106 (10.7\%) developed complications requiring surgery. Patients who were smokers therefore had a significantly higher risk of developing complications requiring surgical revision $(p<0.005)$. The subgroup analysis ( $\triangleright$ Table 5 ) showed that rates for flap-specific complications (total and partial flap loss as well as flap edge necrosis and fat necrosis) were statistically significantly higher in the group of patients who were smokers $(p<0.05)$.

There were no significant differences between subgroups with regard to rates of complications at the abdominal donor site.

\section{Diabetes mellitus, neoadjuvant chemotherapy/ radiotherapy and age}

Patients with a history of diabetes mellitus $(n=5)$, preoperative chemotherapy $(n=760)$ and previous radiation therapy $(n=660)$ did not have a significantly increased risk of developing complications requiring surgery compared to the control group (diabetes mellitus $p>0.05$; radiation therapy $p>0.05$; chemotherapy $p>0,05)$.

There was no statistically significant difference in the incidence of complications requiring surgery between the group of patients aged $\geq 65$ years $(n=60)$ at the time of surgery compared to the group of patients aged $<65$ years $(n=1064)(p>0.05)$. The mean patient age of the group which developed complications requiring surgery was comparable to that of the group without complications requiring surgery $(p>0.05)$ (cf. $>$ Table 5).

All patients were contacted at 3 and 6 months postoperatively and either presented to the outpatient department or were interviewed by telephone and evaluated for the occurrence of seroma or abdominal wall hernia. 945 of 1124 patients (84\%) were followed up for 2 years and 745 (78.5\%) were followed up for 4 years. Twelve patients died. 
- Table 5 Complications differentiated by subgroups.

\begin{tabular}{|c|c|c|c|}
\hline & $\begin{array}{l}\text { Total number of complications } \\
\text { (total number of patients) }\end{array}$ & Percentage & p-value \\
\hline \multicolumn{4}{|l|}{ BMI-related $\left(\mathrm{kg} / \mathrm{m}^{2}\right)$} \\
\hline Underweight (BMI < 18.5) & $0(6)$ & $0 \%$ & \\
\hline \multicolumn{4}{|l|}{ Normal weight (BMI 18.5 to $\leq 25$ ) } \\
\hline - Total number of complications & $43(496)$ & $8.6 \%$ & \\
\hline - Total flap loss & 3 & $0.6 \%$ & \\
\hline - Partial flap loss & 3 & $0.6 \%$ & \\
\hline - Revision & 3 & $0.6 \%$ & \\
\hline - Flap edge necrosis & 8 & $1.6 \%$ & \\
\hline - Fat necrosis & 9 & $1.8 \%$ & \\
\hline - Breast haematoma & 9 & $1.8 \%$ & \\
\hline - Abdominal haematoma & 2 & $0.4 \%$ & \\
\hline - Impaired abdominal wound healing & 3 & $0.6 \%$ & \\
\hline - Seroma & 2 & $0.4 \%$ & \\
\hline - Abdominal wall hernia & 1 & $0.2 \%$ & \\
\hline \multicolumn{4}{|l|}{ Overweight (BMI 25 to $\leq 30$ ) } \\
\hline - Total number of complications & $79(452)$ & $17.5 \%$ & $<0.05^{*}$ \\
\hline - Total flap loss & 4 & $0.9 \%$ & \\
\hline - Partial flap loss & 8 & $1.8 \%$ & \\
\hline - Revision & 2 & $0.4 \%$ & \\
\hline - Flap edge necrosis & 19 & $4.2 \%$ & $<0.05^{*}$ \\
\hline - Fat necrosis & 30 & $6.6 \%$ & $<0.05^{*}$ \\
\hline - Breast haematoma & 7 & $1.5 \%$ & \\
\hline - Abdominal haematoma & 2 & $0.4 \%$ & \\
\hline - Impaired abdominal wound healing & 2 & $0.4 \%$ & \\
\hline - Seroma & 3 & $0.6 \%$ & \\
\hline - Abdominal wall hernia & 2 & $0.4 \%$ & \\
\hline \multicolumn{4}{|l|}{ Obese (BMI 30 to $\geq 40$ ) } \\
\hline - Total number of complications & $26(170)$ & $15.3 \%$ & $<0.05^{*}$ \\
\hline - Total flap loss & 1 & $0.6 \%$ & \\
\hline - Partial flap loss & 1 & $0.6 \%$ & \\
\hline - Revision & 6 & $3.5 \%$ & $<0.05^{*}$ \\
\hline - Flap edge necrosis & 5 & $2.9 \%$ & \\
\hline - Fat necrosis & 8 & $4.7 \%$ & $<0.05^{*}$ \\
\hline - Breast haematoma & 1 & $0.6 \%$ & \\
\hline - Abdominal haematoma & 1 & $0.6 \%$ & \\
\hline - Impaired abdominal wound healing & 2 & $1.1 \%$ & \\
\hline - Seroma & 1 & $0.6 \%$ & \\
\hline - Abdominal wall hernia & 0 & $0.0 \%$ & \\
\hline \multicolumn{4}{|l|}{ Nicotine-related } \\
\hline \multicolumn{4}{|l|}{ Smokers } \\
\hline - Total number of complications & $42(133)$ & $31.6 \%$ & $<0.005^{* *}$ \\
\hline - Total flap loss & 4 & $3.0 \%$ & $<0.05^{*}$ \\
\hline - Partial flap loss & 5 & $3.8 \%$ & $<0.05^{*}$ \\
\hline - Revision & 2 & $1.5 \%$ & \\
\hline - Flap edge necrosis & 10 & $7.5 \%$ & $<0.05^{*}$ \\
\hline - Fat necrosis & 13 & $9.8 \%$ & $<0.05^{*}$ \\
\hline - Breast haematoma & 1 & $0.8 \%$ & \\
\hline - Abdominal haematoma & 2 & $1.5 \%$ & \\
\hline - Impaired abdominal wound healing & 3 & $2.3 \%$ & \\
\hline - Seroma & 2 & $1.5 \%$ & \\
\hline - Abdominal wall hernia & 0 & $0.0 \%$ & \\
\hline
\end{tabular}


- Table 5 Complications differentiated by subgroups. (Continued)

\begin{tabular}{|c|c|c|c|}
\hline & $\begin{array}{l}\text { Total number of complications } \\
\text { (total number of patients) }\end{array}$ & Percentage & p-value \\
\hline \multicolumn{4}{|l|}{ Non-smokers } \\
\hline - Total number of complications & $106(991)$ & $10.7 \%$ & \\
\hline - Total flap loss & 4 & $0.4 \%$ & \\
\hline - Partial flap loss & 7 & $0.7 \%$ & \\
\hline - Revision & 9 & $0.9 \%$ & \\
\hline - Flap edge necrosis & 22 & $2.2 \%$ & \\
\hline - Fat necrosis & 34 & $3.4 \%$ & \\
\hline - Breast haematoma & 16 & $1.6 \%$ & \\
\hline - Abdominal haematoma & 3 & $0.3 \%$ & \\
\hline - Impaired abdominal wound healing & 4 & $0.4 \%$ & \\
\hline - Seroma & 4 & $0.4 \%$ & \\
\hline - Abdominal wall hernia & 3 & $0.3 \%$ & \\
\hline \multicolumn{4}{|l|}{ Diabetes mellitus-related } \\
\hline Diabetes mellitus & $2(5)$ & $40 \%$ & \multirow[t]{2}{*}{$>0.05$} \\
\hline No diabetes mellitus & $146(1119)$ & $13.0 \%$ & \\
\hline \multicolumn{4}{|l|}{ Chemotherapy-related } \\
\hline Chemotherapy & $90(760)$ & $11.8 \%$ & \multirow[t]{2}{*}{$>0.05$} \\
\hline No chemotherapy & $58(364)$ & $15.9 \%$ & \\
\hline \multicolumn{4}{|l|}{ Radiotherapy-related } \\
\hline Radiation therapy & $81(660)$ & $12.3 \%$ & \multirow[t]{2}{*}{$>0.05$} \\
\hline No radiation therapy & $67(464)$ & $14.4 \%$ & \\
\hline \multicolumn{4}{|l|}{ Age-related } \\
\hline Age at surgery $<65$ years & $135(1064)$ & $12.7 \%$ & \multirow[t]{2}{*}{$>0.05$} \\
\hline Age at surgery $\geq 65$ years & $7(60)$ & $11.7 \%$ & \\
\hline
\end{tabular}

\section{Discussion}

The data of this study show that free DIEP flap surgery is an established procedure for autologous breast reconstruction with a low rate of complications. This type of reconstruction is the standard procedure used for breast reconstruction in our department. Even after unsuccessful implant-based reconstruction, autologous tissue reconstruction is a reliable procedure to achieve haptic and visually attractive reconstruction outcomes which approach those of the natural breast $[13,14]$. As reconstruction aims to approximate the changes occurring in a "natural" breast, it is important that the reconstructed breast can also change as the individual ages.

Patients with macromastia or significant breast ptosis of the healthy contralateral breast may require breast reduction of the healthy contralateral side for symmetrisation, with breast reduction performed 2-3 months after autologous reconstruction once the swelling of the reconstructed breast has disappeared and gravity has shifted the flap into its final position. Nipple-areola complex reconstruction with a skate or star flap may be considered after a wait of another 2-3 months to allow the swelling to disappear and gravity to take effect. Final outcomes are usually very close to the visual appearance of the natural breast (cf. examples of patient outcomes in > Figs. 2 to 5).
The rate of total flap loss, which represents a serious complication for patients primarily wanting breast reconstruction was $0.6 \%$ (8 flaps) out of a total of 1274 DIEP flap reconstructions performed by us. The rates of full flap loss after DIEP flap reconstruction given in the literature vary, with rates of up to $5 \%$ being reported [15-18]. Higher flap loss rates can be the result of fewer numbers of surgeries performed annually in a department and therefore a more limited experience of microsurgery. Complication rates can additionally be reduced by the use of a defined algorithm to direct the surgical technique $[19,20]$. The high level of microsurgical expertise and the use of a highly standardised surgical approach which we have used and developed further in our department over the last 10 years may explain the low rate of total flap loss in our department [21]. The rate has remained constantly low despite an annual increase in the number of flap procedures performed in our department.

Another advantage of using a standardised procedure has been the decrease in the duration of surgery over the years. The mean duration of surgery over the entire period of the study was 312 minutes; the mean duration of surgery was 305 minutes for unilateral reconstruction and 436 minutes for bilateral reconstruction. The average time decreased every year until the mean duration of surgery in 2014 was 250 minutes for unilateral and 396 minutes for bilateral breast reconstruction. 

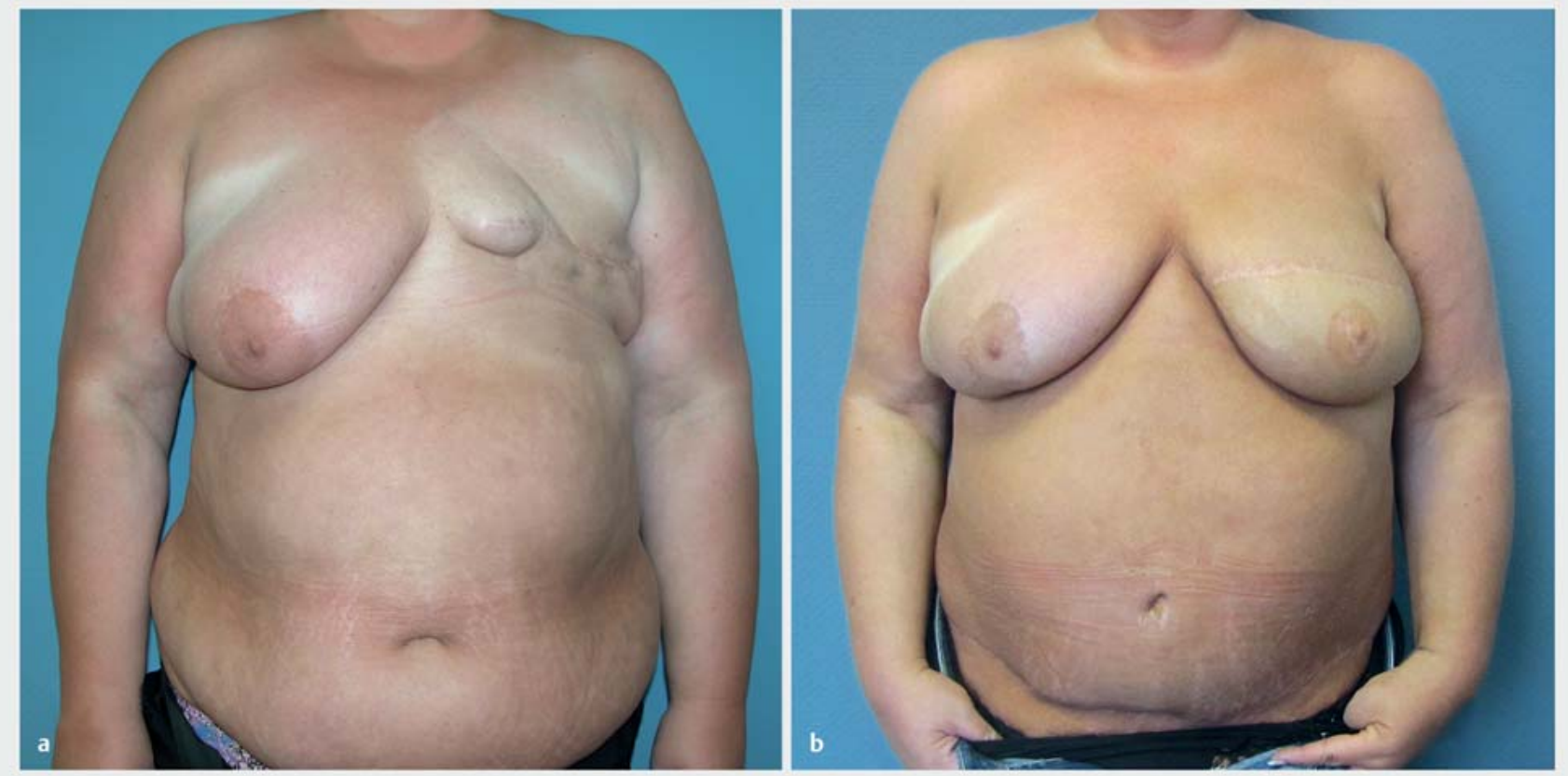

> Fig. 2 a Preoperative findings. Patient aged 44 years, status post left-sided mammectomy. b Postoperative outcome. Patient outcome 49 months after left-sided DIEP flap reconstruction.
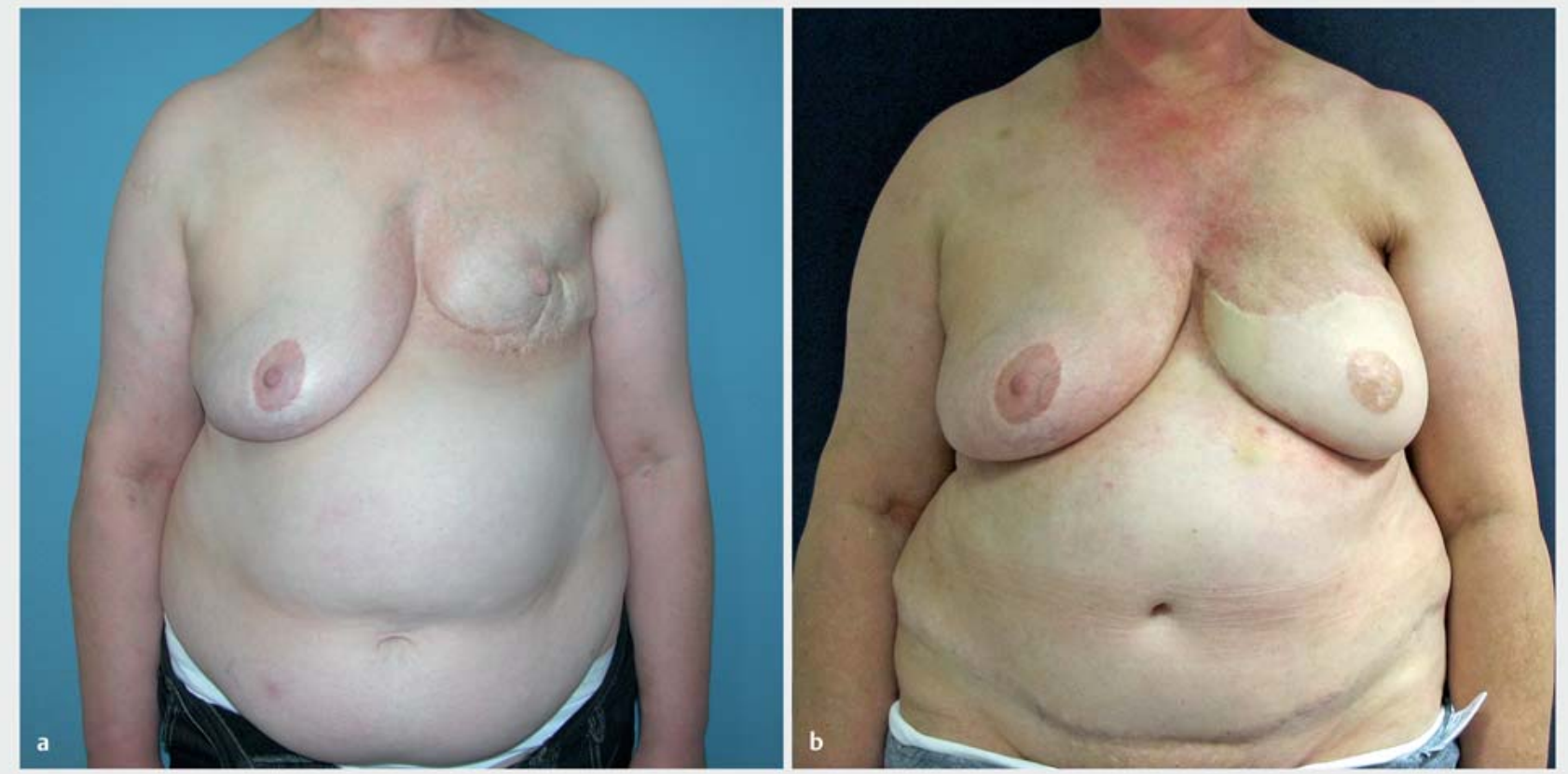

- Fig. 3 a Preoperative findings. Patient aged 52 years, status post left-sided BCT. b Postoperative outcome. Patient outcome 47 months after skin-sparing mastectomy and left-sided DIEP flap reconstruction.

In our study, the group of patients who had had radiation therapy of the affected chest wall preoperatively did not have a significantly higher risk of intra- and postoperative complications com- pared to patients who did not have radiation therapy $(p>0.05)$. Our result differs from that of the retrospective study by Fosnot et al., who carried out 1025 free flap procedures for breast recon- 

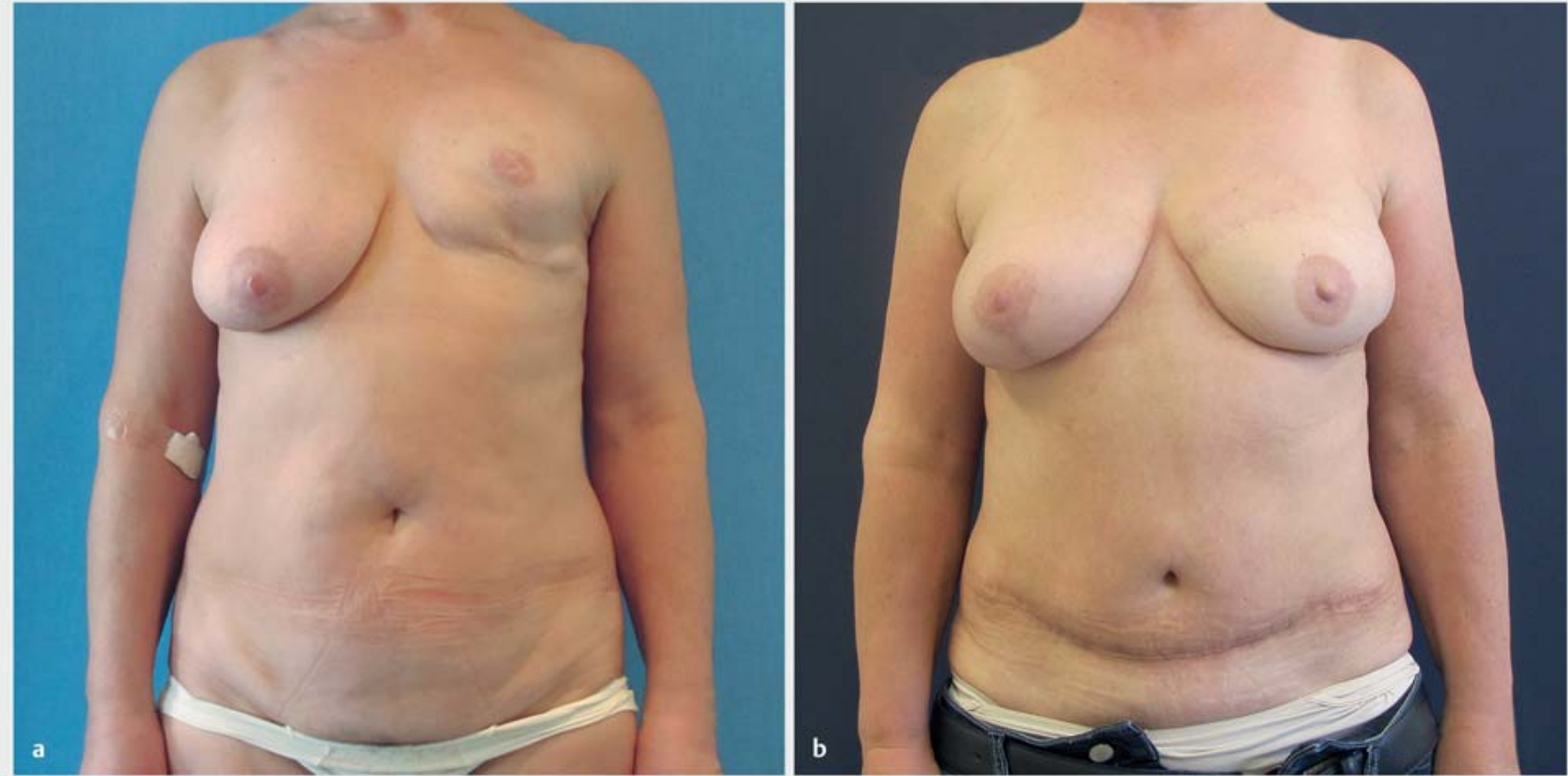

- Fig. 4 a Preoperative findings. Patient aged 56 years, status post prosthetic reconstruction and Baker grade III capsular contracture. b Postoperative outcome. Patient outcome 36 months after prosthesis removal and left-sided DIEP flap reconstruction.
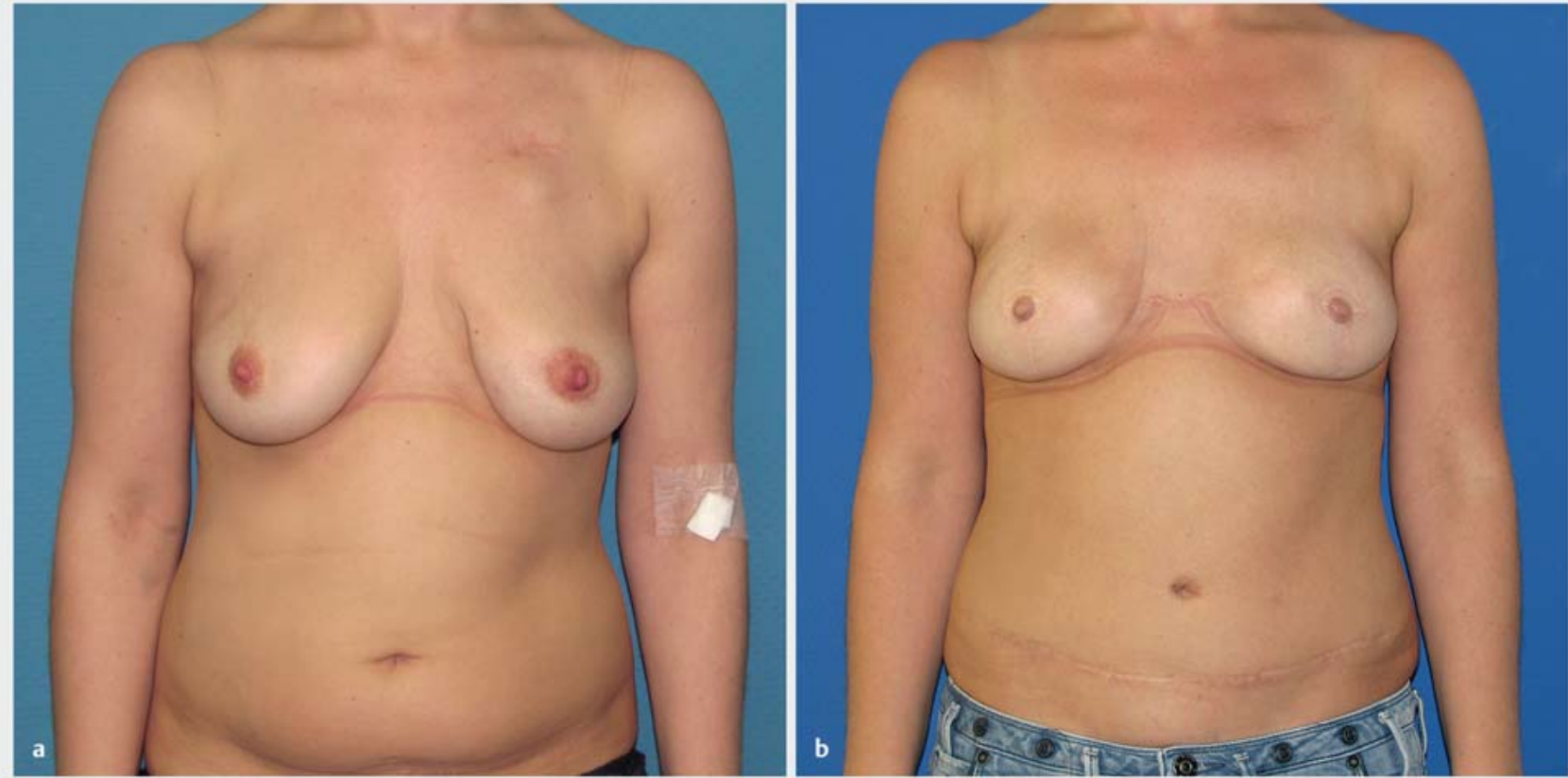

- Fig. 5 a Preoperative findings. Patient aged 32 years prior to prophylactic skin-sparing mastectomy for BRCA1 gene mutation. b Postoperative outcome. Patient outcome 27 months after skin-sparing mastectomy and bilateral DIEP flap reconstruction.

struction. They reported a significantly increased rate of intraoperative vascular complications, although this did not negatively affect final outcomes. However, the occurrence of vascular com- plications may depend on the time between irradiation and microsurgical reconstruction. The risk of vascular complications is particularly high in the period up to 3 months after radiotherapy 
[22]. In a prospective study of 296 flap reconstructions, Baumann et al. showed that a latency period of more than 12 months after the final radiotherapy session reduces the complication rate of microsurgical breast reconstructions compared to reconstructions carried out within the first 12 months after radiotherapy [23]. Based on our experience, a similar reduction in risk is already apparent after a latency period of 6 months between the final radiotherapy session and reconstruction surgery. Autologous tissue reconstruction has also been found to offer benefits compared to implant-based reconstruction in the context of irradiation of the affected chest wall. Patients report that they find the occurrence of capsular fibrosis, which has a reported incidence in the literature of more than $30 \%$ following previous radiotherapy [24-28], as particularly unpleasant, and capsular fibrosis is often the reason cited for a change of surgical procedure.

A thin soft tissue mantle after removal of the mammary gland may be an additional cause of complications in implant-based reconstruction. To solve this problem, almost all implants are placed in a submuscular pocket. In recent years, implant-based reconstructions use matrix materials to strengthen the tissue and provide additional implant coverage over the caudal quadrant and reduce the likelihood of developing capsular fibrosis [29-31]. The problem of breast animation deformities, i.e. breast distortion affecting the shape of the reconstructed breast which can occur after implant-based reconstruction $[32,33]$ with submuscular implant placement, is prevented in reconstruction procedures using autologous tissue and anatomical epipectoral flap positioning [34, 35].

Our study found no significant differences in complication rates occurring in the flap area or the donor site in patients aged more than 65 years at the time of reconstruction compared to the patient cohort which was younger than 65 years. This finding was also confirmed in our earlier studies and by the results of a smaller patient cohort evaluated by Gill et al. $[17,36]$. Studies by Serletti et al. and Malata et al. also showed that higher patient age alone did not constitute an increased risk of complications in free-tissue transfers [37, 38].

We found a significantly higher rate of overall complications in our patient cohort for patients with a higher BMI compared to normal weight patients.

Momeni et al. reported similar findings, showing that patients with a $\mathrm{BMI}>35$ had higher rates of postoperative complications following microsurgical breast reconstruction. However, the majority of complications could be treated conservatively on an outpatient basis [39].

In their retrospective analysis of 352 patients who underwent microsurgical breast reconstruction, Rao et al. also found significantly higher complication rates for patients with a higher BMI [40]. A comparison of subgroups differentiated according to their respective BMI category showed that being overweight (BMI 25 to $\leq 30 \mathrm{~kg} / \mathrm{m}^{2}$ ) or obese (BMI 30 to $\geq 40 \mathrm{~kg} / \mathrm{m}^{2}$ ) was associated with a higher incidence of flap-specific complications, particularly flap edge and fat necrosis $(p<0.05)$. Other studies have reported similar results $[36,41,42]$.

In our department, obese patients presenting for breast reconstruction are explicitly informed about their higher overall risk. Weight loss with a target BMI of about $30 \mathrm{~kg} / \mathrm{m}^{2}$ is recommended and described as a prerequisite for surgery. In individual cases, patients may be supported to lose weight by undergoing obesity therapy with professional nutrition counselling.

Smoking is also associated with a higher rate of wound healing disorders [41-43]. This was already shown in an older study carried out in our department [36]. A significantly increased rate of postoperative complications was apparent in this most recent cohort of patients who were smokers at the time of surgery, and the difference in terms of the rate of overall complications was statistically highly significant $(p<0.005)$. As in the BMI subgroup analysis, the subgroup analysis of smokers versus non-smokers showed that smokers had a higher incidence of flap-related complications (flap edge and fat necrosis as well as total or partial flap loss), and this difference was statistically significant $(p<0.05)$.

In their study of 748 patients who underwent breast reconstruction, Padubidri et al. were able to show that non-smokers and former smokers (defined as patients who had not smoked for at least 3 weeks preoperatively) had lower complication rates compared to smokers [44]. Our patients are instructed to stop smoking for at least 6 weeks prior to surgery.

\section{Summary}

Overall, our study shows that, over the observation period of more than 10 years since our department was created, autologous tissue breast reconstruction with a DIEP flap procedure carried out in a specialised interdisciplinary breast centre in a standardised setting by an experienced microsurgical team is a reliable procedure for autologous breast reconstruction with a low rate of complications and low donor site morbidity. One result of standardising the surgical approach has been a reduction in the duration of surgery. Higher BMI and smoking were found to be statistically significant risk factors. Higher age, chemotherapy, and radiotherapy did not constitute a significant risk in our patient cohort. The DIEP flap procedure for autologous breast reconstruction creates a "dynamic" individually ageing, haptic and aesthetically pleasing breast with satisfactory results over the long term.

\section{Conflict of Interest}

The authors declare that they have no conflict of interest.

\section{References}

[1] Robert Koch-Institut (RKI); Zentrum für Krebsregisterdaten. Bericht zum Krebsgeschehen in Deutschland 2016. Online: http://edoc.rki.de/ 176904/3264; last access: 01.02.2020

[2] Anderson BO, Masetti R, Silverstein MJ. Oncoplastic approaches to partial mastectomy: an overview of volume-displacement techniques. Lancet Oncol 2005; 6: 145-157

[3] Franceschini G, Terribile D, Magno $S$ et al. Conservative treatment of the central breast cancer with nipple-areolar resection: an alternative oncoplastic technique. G Chir 2008; 29: 23-27

[4] Liu C, Zhuang Y, Momeni A et al. Quality of life and patient satisfaction after microsurgical abdominal flap versus staged expander/implant breast reconstruction: a critical study of unilateral immediate breast reconstruction using patient-reported outcomes instrument BREAST-Q. Breast Cancer Res Treat 2014; 146: 117-126 
[5] King MC, Marks JH, Mandell JB; New York Breast Cancer Study Group. Breast and ovarian cancer risks due to inherited mutations in BRCA1 and BRCA2. Science 2003; 302: 643-646

[6] Struewing JP, Hartge P, Wacholder S et al. The risk of cancer associated with specific mutations of BRCA1 and BRCA2 among Ashkenazi Jews. N Engl J Med 1997; 336: 1401-1408

[7] Chen S, Parmigiani G. Meta-analysis of BRCA1 and BRCA2 penetrance. J Clin Oncol 2007; 25: 1329-1333

[8] Hartrampf CR, Scheflan M, Black PW. Breast reconstruction with a transverse abdominal island flap. Plast Reconstr Surg 1982; 69: 216-225

[9] Grotting JC, Urist MM, Maddox WA et al. Conventional TRAM flap versus free microsurgical TRAM flap for immediate breast reconstruction. Plast Reconstr Surg 1989; 83: 828-841; discussion 842-844

[10] Koshima I, Soeda S. Inferior epigastric artery skin flaps without rectus abdominis muscle. Br J Plast Surg 1989; 42: 645-648

[11] Allen RJ, Treece P. Deep inferior epigastric perforator flap for breast reconstruction. Ann Plast Surg 1994; 32: 32-38

[12] Blondeel PN, Boeckx WD. Refinements in free flap breast reconstruction: the free bilateral deep inferior epigastric perforator flap anastomosed to the internal mammary artery. Br J Plast Surg 1994; 47: 495-501

[13] Thamm OC, Andree C. Immediate versus Delayed Breast Reconstruction - Evolving Concepts and Evidence. Clin Plast Surg 2018; 45: 119-127

[14] Otte M, Nestle-Krämling C, Fertsch S et al. Conservative mastectomies and Immediate-DELayed AutoLogous (IDEAL) breast reconstruction: the DIEP flap. Gland Surg 2016; 5: 24-31

[15] Granzow JW, Levine JL, Chiu ES et al. Breast reconstruction with the deep inferior epigastric perforator flap: history and an update on current technique. J Plast Reconstr Aesthet Surg 2006; 59: 571-579

[16] Blondeel PN. One hundred free DIEP flap breast reconstructions: a personal experience. Br J Plast Surg 1999; 52: 104-111

[17] Gill PS, Hunt JP, Guerra AB et al. A 10-year retrospective review of 758 DIEP flaps for breast reconstruction. Plast Reconstr Surg 2004; 113: 1153-1160

[18] Keller A. The deep inferior epigastric perforator free flap for breast reconstruction. Ann Plast Surg 2001; 46: 474-479; discussion 479-480

[19] Damen TH, Morritt AN, Zhong T et al. Improving outcomes in microsurgical breast reconstruction: Lessons learnt from 406 consecutive DIEP/ TRAM flaps performed by a single surgeon. J Plast Reconstr Aesthet Surg 2013; 66: 1032-1038

[20] Lindsey JT. Integrating the DIEP and muscle-sparing (MS-2) free TRAM techniques optimizes surgical outcomes: presentation of an algorithm for microsurgical breast reconstruction based on perforator anatomy. Plast Reconstr Surg 2007; 119: 18-27

[21] Langer S, Munder B, Seidenstuecker K et al. Development of a surgical algorithm and optimized management of complications - based on a review of 706 abdominal free flaps for breast reconstruction. Med Sci Monit 2010; 16: Cr518-Cr522

[22] Fosnot J, Fischer JP, Smartt JM jr. et al. Does previous chest wall irradiation increase vascular complications in free autologous breast reconstruction? Plast Reconstr Surg 2011; 127: 496-504

[23] Baumann DP, Crosby MA, Selber JC et al. Optimal timing of delayed free lower abdominal flap breast reconstruction after postmastectomy radiation therapy. Plast Reconstr Surg 2011; 127: 1100-1106

[24] Ersek RA. Rate and incidence of capsular contracture: a comparison of smooth and textured silicone double-lumen breast prostheses. Plast Reconstr Surg 1991; 87: 879-884
[25] Ersek RA, Salisbury AV. Textured surface, nonsilicone gel breast implants: four years' clinical outcome. Plast Reconstr Surg 1997; 100: 1729-1739

[26] Gabriel SE, Woods JE, O'Fallon WM et al. Complications leading to surgery after breast implantation. N Engl J Med 1997; 336: 677-682

[27] Spear SL, Murphy DK, Slicton A et al.; Inamed Silicone Breast Implant U.S. Study Group. Inamed silicone breast implant core study results at 6 years. Plast Reconstr Surg 2007; 120: 8S-16S; discussion 17S-18S

[28] Cunningham B. The Mentor Core Study on Silicone MemoryGel Breast Implants. Plast Reconstr Surg 2007; 120: 19S-29S; discussion 30S-32S

[29] Kronowitz S]. Current status of implant-based breast reconstruction in patients receiving postmastectomy radiation therapy. Plast Reconstr Surg 2012; 130: 513e-523e

[30] Basu CB, Jeffers L. The role of acellular dermal matrices in capsular contracture: a review of the evidence. Plast Reconstr Surg 2012; 130: 118S$124 \mathrm{~S}$

[31] Slavin SA, Lin SJ. The use of acellular dermal matrices in revisional breast reconstruction. Plast Reconstr Surg 2012; 130: 70S-85S

[32] Hammond DC, Schmitt WP, O'Connor EA. Treatment of breast animation deformity in implant-based reconstruction with pocket change to the subcutaneous position. Plast Reconstr Surg 2015; 135: 1540-1544

[33] Spear SL, Schwartz J, Dayan JH et al. Outcome assessment of breast distortion following submuscular breast augmentation. Aesthetic Plast Surg 2009; 33: 44-48

[34] de Benito J, Sanchez K. Secondary breast augmentation: managing each case. Aesthetic Plast Surg 2010; 34: 691-700

[35] Wolter A, Andree C. Korrekturmöglichkeiten bei Brustimplantatfehlposition. Plastische Chirurgie 2019; 1: 26-33

[36] Seidenstuecker K, Munder B, Mahajan AL et al. Morbidity of microsurgical breast reconstruction in patients with comorbid conditions. Plast Reconstr Surg 2011; 127: 1086-1092

[37] Serletti JM, Higgins JP, Moran S et al. Factors affecting outcome in freetissue transfer in the elderly. Plast Reconstr Surg 2000; 106: 66-70

[38] Malata CM, Cooter RD, Batchelor AG et al. Microvascular free-tissue transfers in elderly patients: the Leeds experience. Plast Reconstr Surg 1996; 98: 1234-1241

[39] Momeni A, Ahdoot MA, Kim RY et al. Should we continue to consider obesity a relative contraindication for autologous microsurgical breast reconstruction? J Plast Reconstr Aesthet Surg 2012; 65: 420-425

[40] Rao S, Stolle EC, Sher S et al. A multiple logistic regression analysis of complications following microsurgical breast reconstruction. Gland Surg 2014; 3: 226-231

[41] Timmermanns FW, Westland PB, Hummelink S et al. A retrospective investigation of abdominal visceral fat, body mass index (BMI), and active smoking as risk factors for donor site wound healing complications after free DIEP flap breast reconstructions. J Plast Reconstr Aesthet Surg 2018; 71: 827-832

[42] Klasson S, Nyman J, Svensson H et al. Smoking increases donor site complications in breast reconstruction with DIEP flap. J Plast Surg Hand Surg 2016; 50: 331-335

[43] Lawrence WT, Murphy RC, Robson MC et al. The detrimental effect of cigarette smoking on flap survival: an experimental study in the rat. $\mathrm{Br}$ J Plast Surg 1984; 37: 216-219

[44] Padubidri AN, Yetman R, Browne E et al. Complications of postmastectomy breast reconstructions in smokers, ex-smokers, and nonsmokers. Plast Reconstr Surg 2001; 107: 342-349; discussion 350-351 